\title{
Numerical Modelling Study of Behaviour of Consolidated Strata Around Tunnel
}

\author{
Nalini Rebello ${ }^{\star}$, Vedala Rama Sastry ${ }^{2}$ and Shivashankar $\mathbf{R}^{3}$ \\ ${ }^{1,3}$ Department of Civil Engineering, National Institute of Technology Karnataka, Surathkal, India \\ ${ }^{2}$ Department of Mining Engineering, National Institute of Technology Karnataka, Surathkal, India
}

\begin{tabular}{|c|c|}
\hline Abstract & Article Information \\
\hline \multirow{13}{*}{$\begin{array}{l}\text { Tunnelling in densely populated areas and under existing buildings is common in most } \\
\text { of the cities around the world. Upon excavation there are changes that take place in } \\
\text { the soil /rock mass and these changes can have an impact on the surface structures. } \\
\text { In this paper an attempt is made to assess the behavior of the tunnel in given } \\
\text { environment and the associated displacements due to tunneling in a highly } \\
\text { consolidated soil/rock mass with two different conditions of earth pressure coefficient. } \\
\text { A case study of a tunnel in South India was taken up for studies. } 3 \text {-dimensional } \\
\text { Distinct Element Modelling code was used for the analysis. In the first stage, earth } \\
\text { pressure coefficient Ko of } 2.2 \text { was taken for the top layers and } 1.8 \text { for bottom layers. In } \\
\text { the second stage, a value of } 2.2 \text { was considered throughout the model. In the third } \\
\text { stage displacement generated in the transverse direction, in the presence and } \\
\text { absence of the building load was taken into consideration and analysed. Vertical } \\
\text { displacements were found to be of considerable magnitude at the crown, showing a } \\
\text { decreasing trend towards the surface. Horizontal displacements were of negligible } \\
\text { magnitude along the depth. However, maximum displacement was noted at the } \\
\text { springing level of the tunnel. Models incorporating weight of buildings showed no } \\
\text { noticeable increase in the settlements, as the soil/rock mass is already consolidated. }\end{array}$} & Article History: \\
\hline & Received : 12-03-2014 \\
\hline & : 19-06-2014 \\
\hline & Accepted : 22-06-2014 \\
\hline & Keywords: \\
\hline & Numerical modeling \\
\hline & 3 Dimensional \\
\hline & Distinct Element code \\
\hline & Earth pressure coefficients \\
\hline & ${ }^{*}$ Corresponding Author: \\
\hline & Nalini Rebello \\
\hline & \\
\hline & \\
\hline
\end{tabular}

\section{INTRODUCTION}

Design of tunnels requires considerable amount of geotechnical investigations and planning prior to the commencement of the construction process. The alignment, depth and size of the tunnel should be so selected that the tunnel is the most stable and suits the terrain, the geological features of the area and the purpose for which the tunnel is constructed. In case of tunnels in shallow depths, the overlying soil which is consolidated under buildings and other structures will also create additional stresses upon excavation. Many researchers have performed field monitoring to investigate the change in stresses upon excavation (Attewell, 1978; Lee and Rowe, 1990 and Peck, 1969), in clayey soils. However very few researchers have carried out detailed studies of tunnel excavation in layered soils and rocks.

Effective prediction of the displacement around the opening forms a major input for effective progress of tunnel and designing a suitable support system. Support system can thus be designed to cater to the additional stresses developed during the excavation resulting in reduction of stress related hindrances during construction. As the depth of overburden increases, there may be insignificant changes in the stress redistribution around the opening. The change in the stress conditions at shallow depth where both soil and rock mass are encountered is an important aspect to be studied in depth. An attempt was made to assess the change in stress condition upon excavating tunnels in layered soils and rocks at shallow depths in South India. Distinct Element Modeling study was carried out for simulating different conditions of the tunnel and further analysis of the same (Dursun et al., 2008).

Traffic in most of the major cities of the country is rising at an alarming rate, triggering the increase in congestion and pollution levels in the city. An effective immediate solution for this ever growing traffic congestion is adopting one of the mass rapid transit systems available, involving underground mode of transport through tunnels at different places. Whenever tunnels are planned for mass rapid transport system in a thickly populated city, the transport system weaves through the bustling commercial and residential areas of the city. Study of the behavior of rock mass / strata around tunnels becomes a very essential component in such cases for the design of tunnels. Case study of a tunnel in Bangalore was taken up for the studies. Analysis was carried out for a stretch of $300 \mathrm{~m}$ with varying geotechnical and loading conditions encountered (Liu et al., 2000; Kasper et al., 2006) 
Nalini Rebello et al.,

\section{MATERIALS AND METHODS}

Numerical Modelling of the Tunnel

Simulation study was carried out using 3DEC software. 3DEC is based upon a command-driven format. Word commands control the operation of the program. In order to set up a model to run a simulation with 3DEC, three fundamental components of a problem must be specified:

1. A Distinct-Element Model that matches the problem geometry.

2. Constitutive behavior and material properties.

3. Boundary and initial conditions.

The model block defines the geometry of the problem. The constitutive behavior and associated material properties dictate the type of response the model will
Sci. Technol. Arts Res. J., April-June 2014, 3(2): 190-196

display upon disturbance (e.g. deformational response due to excavation). Boundary and initial conditions define the in-situ state (i.e. the condition before a change or disturbance in problem state is introduced). After these conditions are defined in 3DEC, an alteration is made (e.g. excavate material or change boundary conditions), and the resulting response of the model is analyzed. Solution is reached after a series of computational steps. In 3DEC, the number of steps required to reach a solution is controlled manually by the user (3DEC Manual, 2004).

Numerical modeling was carried out from 0 to $340 \mathrm{~m}$ with the tunnel starting from Chainage 20 to $320 \mathrm{~m}$. The borehole logs along the length of the tunnel are shown in Figure 1.

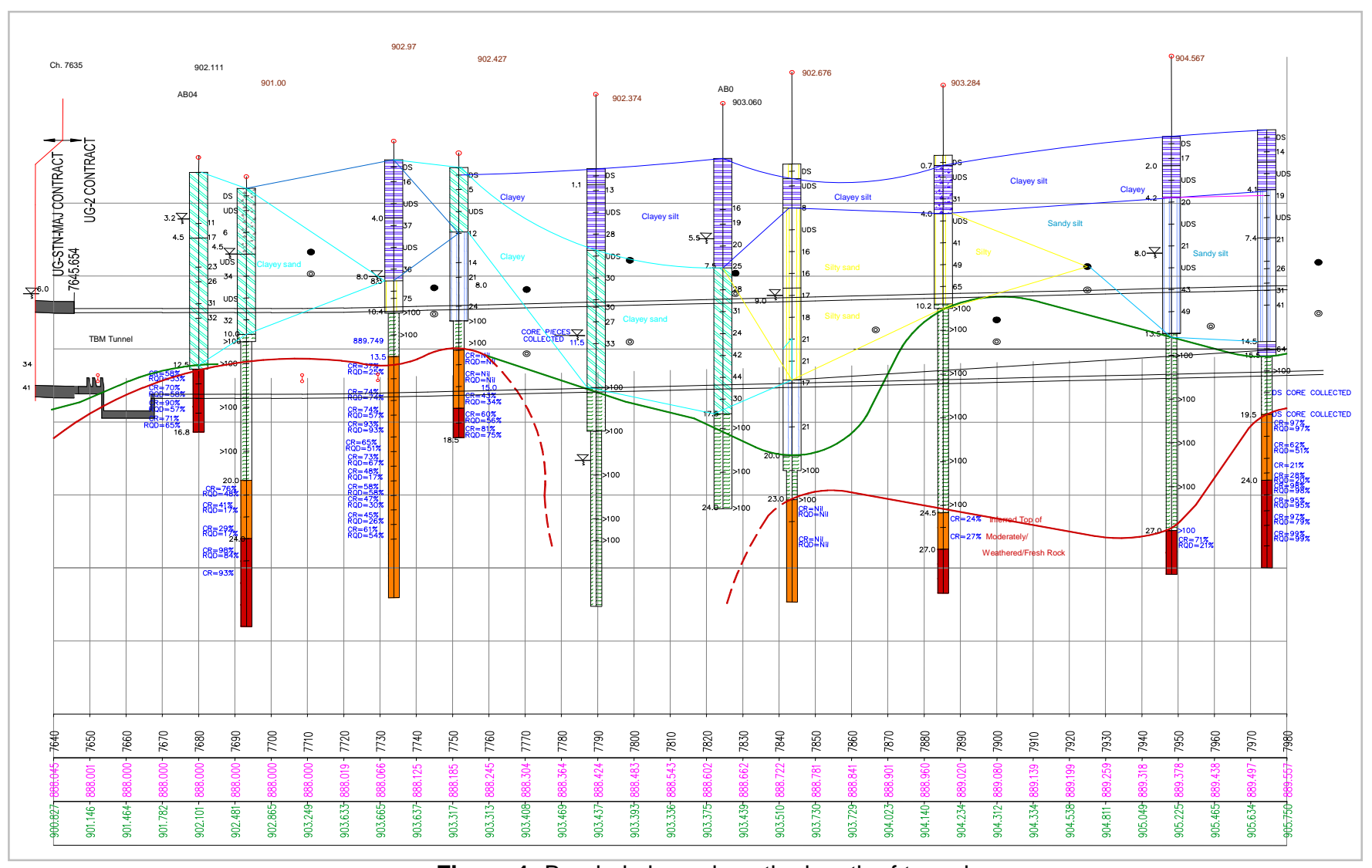

Figure 1: Borehole logs along the length of tunnel

A goood approximation of the deformational response of the rock mass was obtained by fixing boundaries of the model of at least five times the major dimensions. The boundary elements were modeled as fixed supports at the bottom and sides were modeled as roller supports. Since the rock mass behaves non-linearly with the loading conditions, an elasto-plastic model was considered using Mohr-Coloumb criterion. A linear elastic model was considered for the tunnel liner.

The developed models comprised of tetrahedral zones for rock mass/soil mass. Stiffness of upper layers of the formation was made almost equal to that of the underlying rock mass assuming consolidation to have taken place already. The Physico-mechanical properties assigned at different chainages of the proposed tunnel are given in Table 1. These properties are almost similar at the other chainages of the rock mass as well.
At Ch. $20 \mathrm{~m}$ the tunnel passes only through different layers of soil and does not pass through rock. The $R L$ at tunnel crown is 36.1

At Ch. $67 \mathrm{~m}$ the crown of tunnel is at $R L 36.3$ and moderately weathered rock starts from $R L 32$ which is about $2 \mathrm{~m}$ above the invert

At Ch. $117 \mathrm{~m}$ the crown of tunnel is at 36.4 and moderately weathered rock starts at $\mathrm{RL} 34.4$

At Ch. $167 \mathrm{~m}$ the crown of tunnel is at 36.6 and rock starts at $\mathrm{RL} 31.2$

At Ch. $217 \mathrm{~m}$ the crown is at $\mathrm{RL} 36.9$ and rock starts at RL 34

At Ch. $267 \mathrm{~m}$ the crown starts at $\mathrm{RL} 37.2$ and rock at 35.8

At Ch. $317 \mathrm{~m}$ the crown is at $\mathrm{RL} 37$ and rock starts at 34 
Table 1: Physico-mechanical properties of strata from chainage $0 \mathrm{~m}$ to $340 \mathrm{~m}$

\begin{tabular}{|c|c|c|c|c|c|}
\hline $\begin{array}{l}\text { Soil /Rock } \\
\text { Type }\end{array}$ & $\begin{array}{l}\text { Bulk Modulus } \\
(\mathrm{Pa})\end{array}$ & $\begin{array}{c}\text { Rigidity } \\
\text { Modulus (Pa) }\end{array}$ & $\begin{array}{c}\text { Mass Density } \\
\left(\mathrm{kg} / \mathrm{m}^{3}\right)\end{array}$ & $\begin{array}{c}\text { Cohesion } \\
(\mathrm{Pa})\end{array}$ & $\begin{array}{c}\text { Coefficient of } \\
\text { Internal Friction }\end{array}$ \\
\hline $1^{\text {st }}$ layer & $1.83 e^{8}$ & $1.375 e^{8}$ & 1800 & $12 e^{3}$ & 25 \\
\hline $2^{\text {nd }}$ layer & $4.8 e^{8}$ & $2.15 e^{8}$ & 2000 & $15 e^{3}$ & 34 \\
\hline $3^{\text {rd }}$ layer & $8 e^{y}$ & $3.2 e^{y}$ & 2300 & $17 e 3$ & 36 \\
\hline $4^{\text {th }}$ layer & $4.75 e^{9}$ & $2.19 e^{9}$ & 2200 & $14 e^{3}$ & 33 \\
\hline $5^{\text {th }}$ layer & $3.3 e^{10}$ & $1.2 e^{10}$ & 2400 & $2 e^{6}$ & 50 \\
\hline $6^{\text {th }}$ layer & $4.3 e^{10}$ & $2 e^{10}$ & 2500 & $1.5 e^{6}$ & 55 \\
\hline
\end{tabular}

The vertical displacement was plotted along the centre line of the tunnel starting from the surface to the crown for all chainages of $67 \mathrm{~m}, 117 \mathrm{~m}, 167 \mathrm{~m}, 217 \mathrm{~m}, 267 \mathrm{~m}$ and $400 \mathrm{~m}$. The horizontal displacements were also plotted at a distance of $3 \mathrm{~m}$ from the centre of tunnel for all the chainages. Modelling was carried out at two different values of earth pressure conditions. In the first model the top layers of the soil were assigned a Ko value of 2.2 and the bottom layers, at the tunnel level, were assigned a Ko value of 1.8. The model was also checked for change in settlement due to building loads. In the second model a uniform value of earth pressure coefficient of $\mathrm{Ko}=2.2$ was assigned. Figure 2 shows the varying layers of the soil mass created in the numerical model. Building load was applied as uniform pressure acting over the location of buildings.

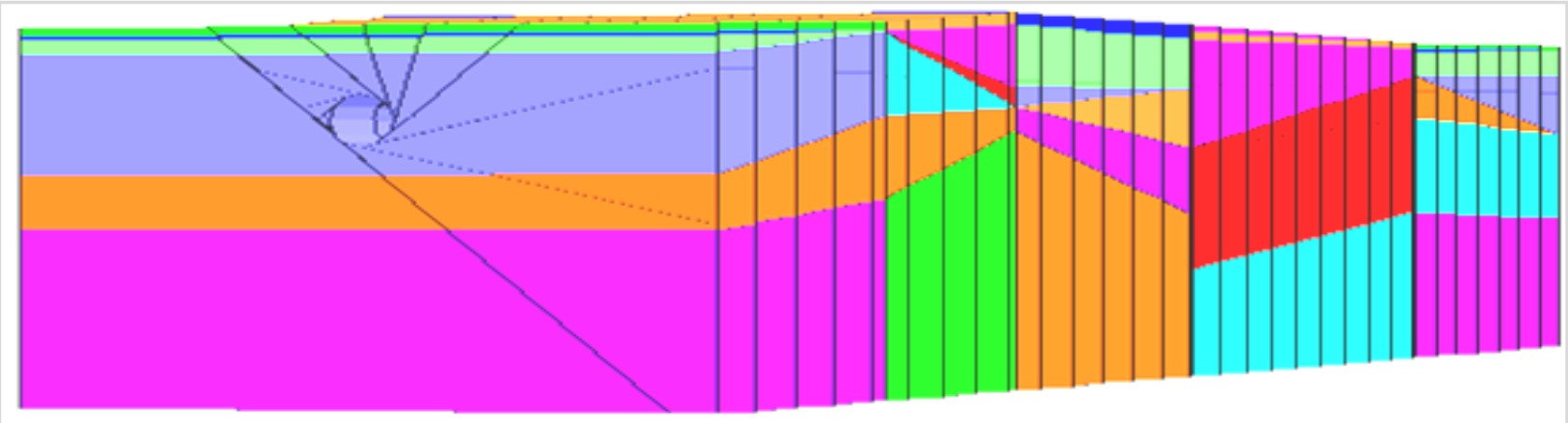

Figure 2: Numerical model of the tunnel

\section{RESULTS}

Stage - 1: Effect of tunneling at chainages 20 to $320 \mathrm{~m}$

Tunnels at Ch. $67 \mathrm{~m}$ are at axis depth of less than 2D (where ' $D$ ' is the diameter of the tunnel) from the surface whereas tunnels at the other chainages are greater than 2D from the surface. In stage 1 effects of tunnelling are analysed for both cases of earth pressure coefficient.

\section{Effect of tunnel excavation on stability at $\mathrm{Ch} .67 \mathrm{~m}$}

At this chainage, $4 \mathrm{~m}$ of the tunnel passes through soil mass and the bottom $2 \mathrm{~m}$ passes through rock mass. The centre of the tunnel is at a depth of less than 2D from the surface. Maximum vertical displacement of $-10.5 \mathrm{~mm}$ is noted at the tunnel crown and a horizontal displacement of $10.73 \mathrm{~mm}$ is observed at the springing level. The horizontal inward movement at the springing level is not resisted by the soil mass and thus a downward movement is noted at the tunnel crown. The displacement at the tunnel crown is not reflected to the surface. A displacement of magnitude $-0.15 \mathrm{~mm}$ is noted at the surface which is just $1.455 \%$ of the displacement at the crown. The values are almost similar for the second case of Ko condition (Figures 3 and 4).

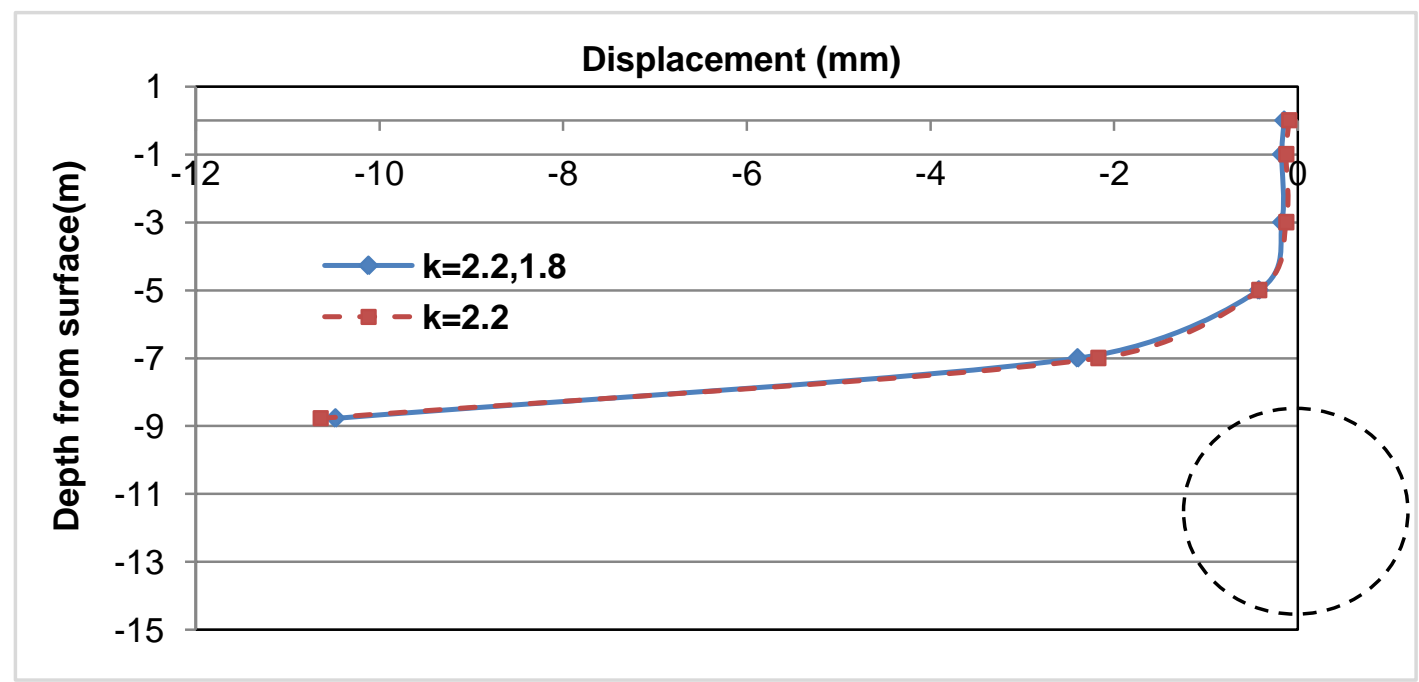

Figure 3: Vertical displacement along the depth at Ch. $67 \mathrm{~m}$ 


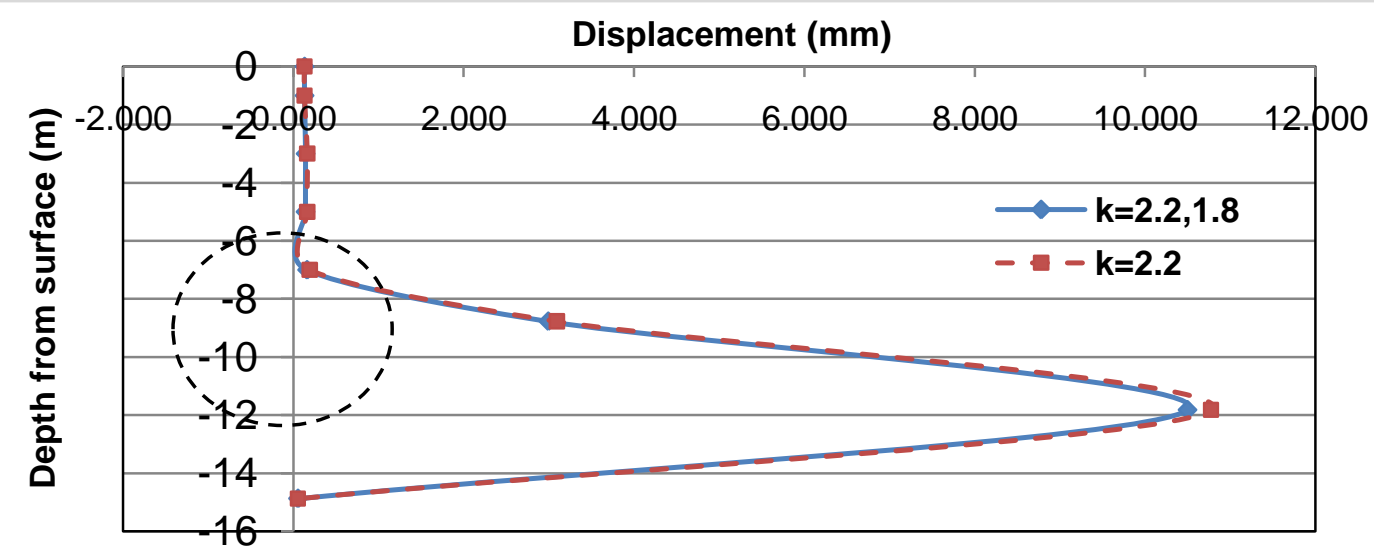

Figure 4: Horizontal displacement along depth of the tunnel at Ch. $67 \mathrm{~m}$.

Effect of tunnel excavation on stability at $\mathrm{Ch} .117 \mathrm{~m}$.

The tunnel centre is at a depth greater than $2 \mathrm{D}$ from the surface. The tunnel is predominantly in rock mass, with $4 \mathrm{~m}$ depth from the bottom in rock. A horizontal displacement of magnitude $7.5 \mathrm{~mm}$ is noted at the springing level and the vertical displacement at the crown is $-1.48 \mathrm{~mm}$ (Figures 5 and 6 ). Reduced magnitude of vertical displacement at the crown can be attributed to the presence of rock mass at shallow depth. Vertical displacement at the surface is $-0.28 \mathrm{~mm}$ which is $18.95 \%$ of the crown displacement.

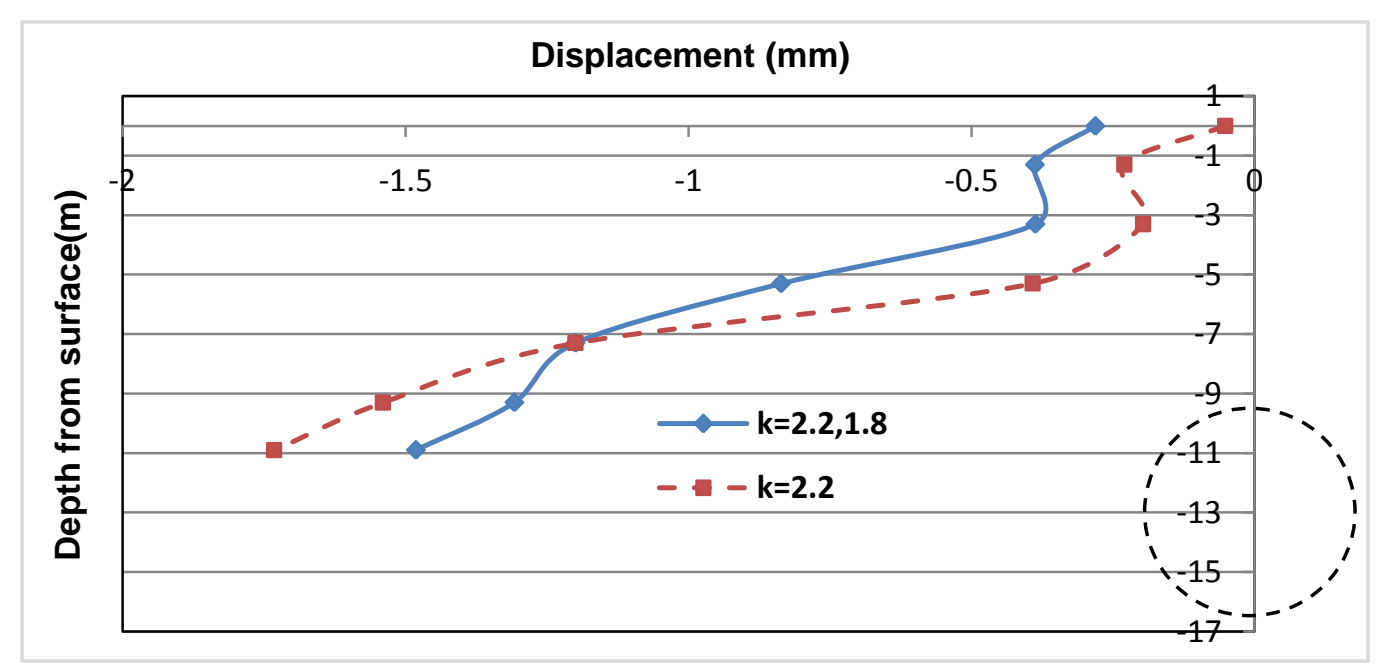

Figure 5: Vertical displacement along the depth at Ch. $117 \mathrm{~m}$

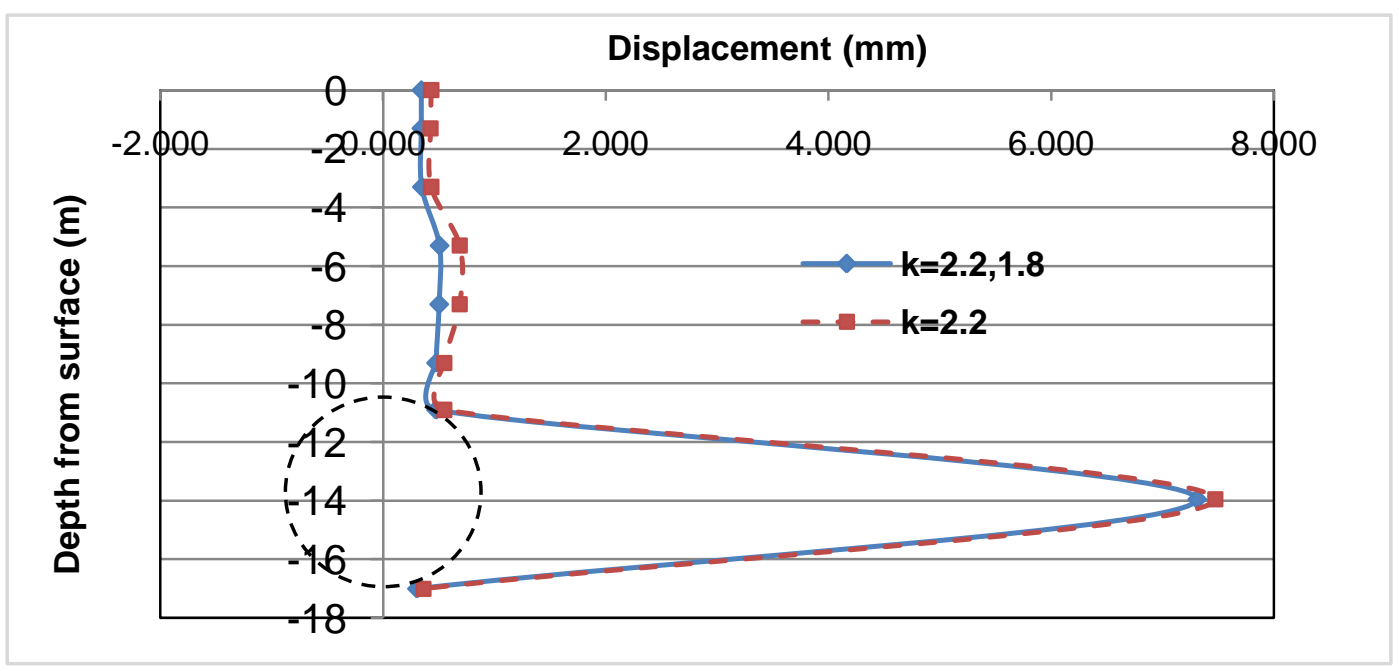

Figure 6: Horizontal displacement along the depth of the tunnel at Ch. $117 \mathrm{~m}$ 
Nalini Rebello et al.,

Effect of tunnel excavation on stability at Ch. 167m

Once again the tunnel encounters rock mass at a depth of $5 \mathrm{~m}$ from the crown. So the excavation is predominantly in soil mass and the horizontal displacement at springing level is $15.2 \mathrm{~mm}$ and the vertical downward displacement of magnitude $13.5 \mathrm{~mm}$ is noticed at the crown. The large magnitude of horizontal pressure
Sci. Technol. Arts Res. J., April-June 2014, 3(2): 190-196

has no effect on the upward movement of crown since arching effect is quite predominant at centre line depths greater than 2D from surface. The surface displacement is $4.37 \%$ of displacements at the crown. The displacements are similar to displacements at Ch. $117 \mathrm{~m}$ ( Figures 7 and 8).

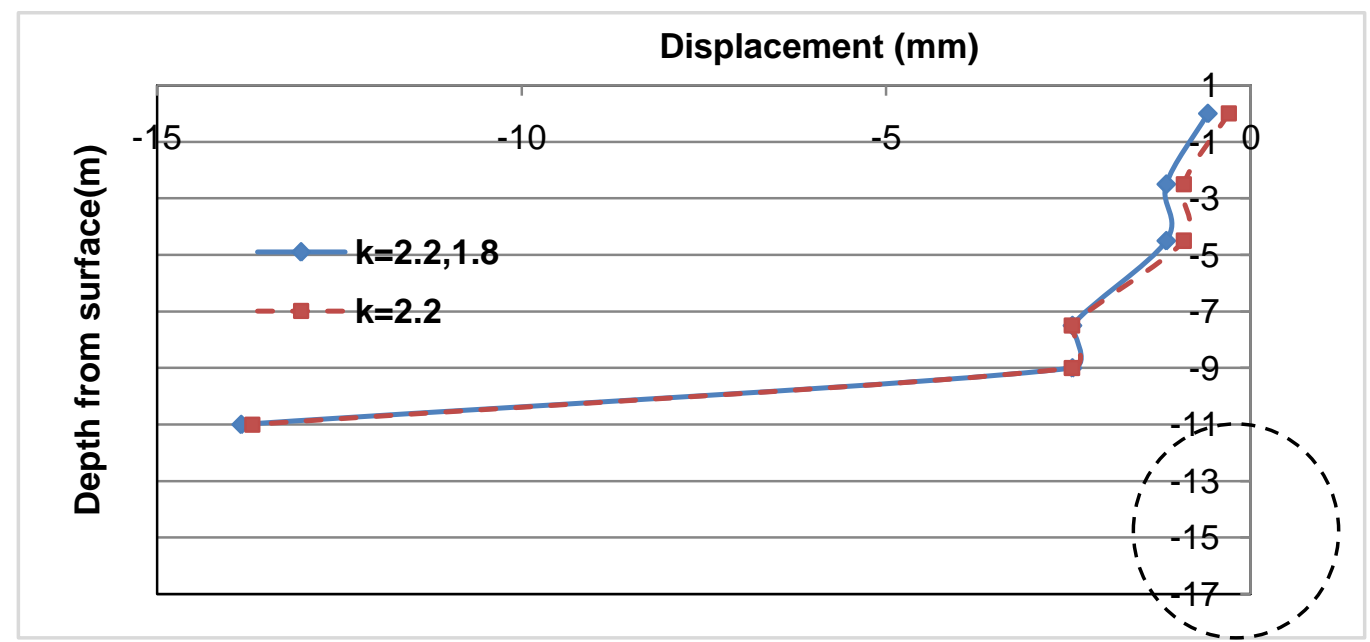

Figure 7: Vertical displacement along the depth of the tunnel at Ch. $167 \mathrm{~m}$.

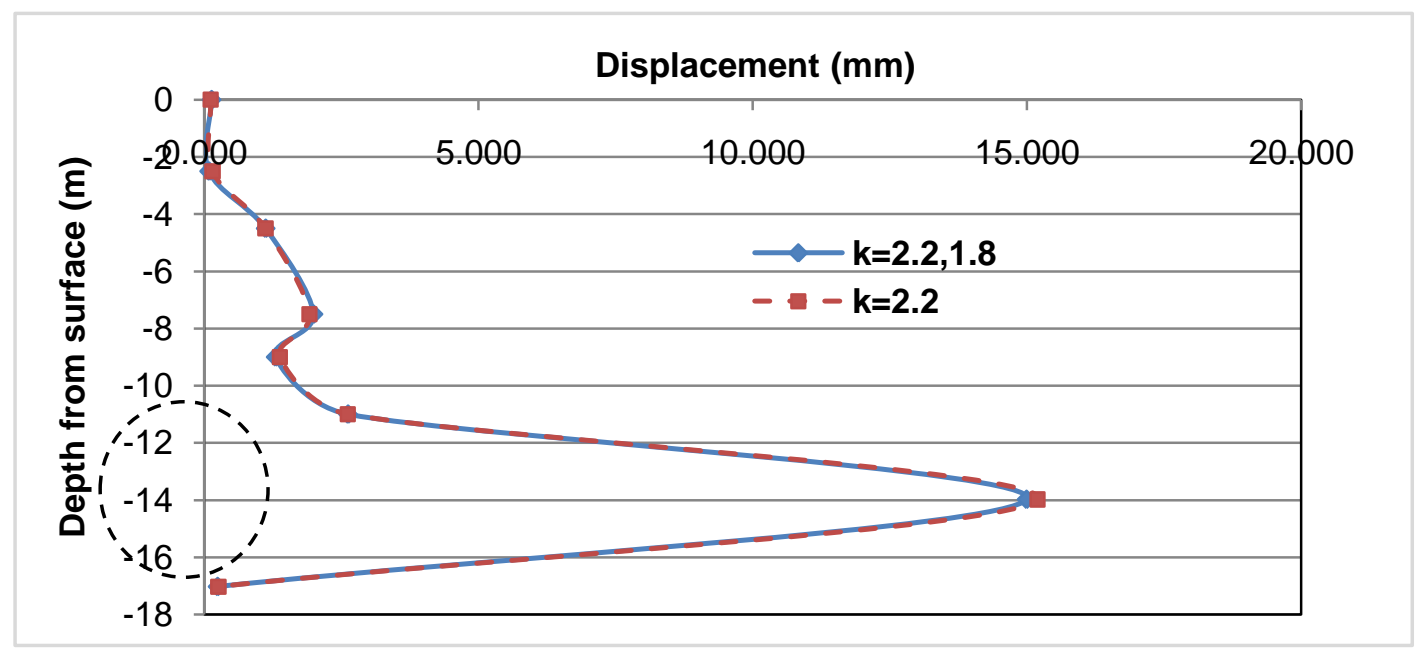

Figure 8: Horizontal displacement along the depth of the tunnel at Ch. 167m

\section{Effect of tunnel excavation on stability at $\mathrm{Ch} .217 \mathrm{~m}$}

At this Chainage the tunnel encounters rock mass for the lower half portion and soil mass for the upper half. A horizontal displacement of $0.12 \mathrm{~mm}$ is noticed at springing level and vertical displacement at the tunnel crown is of magnitude $-7.5 \mathrm{~mm}$ (Figures 9 and 10). The displacement at the surface is $0.29 \mathrm{~mm}$ in the downward direction, with only $3.86 \%$ of crown displacement reflected at the surface.

\section{Effect of tunnel excavation on stability at Ch. $267 \mathrm{~m}$}

At this Chainage the soil profile is almost similar to that of $\mathrm{Ch} .217 \mathrm{~m}$. The tunnel encounters rock mass for the lower half portion and soil mass for the upper half. A horizontal displacement of magnitude $2 \mathrm{~mm}$ is noticed at springing level and vertical displacement at the tunnel crown is of magnitude $-1.05 \mathrm{~mm}$ (Figures 11 and 12). A $0.12 \mathrm{~mm}$ magnitude of vertical downward displacement is noted at the surface which is only $11.3 \%$ of crown displacement.
Stage-2: Effect of excavation with building loads on the settlement profile.

The vertical displacement plots normal to the tunnel direction are shown in Figure 13. The displacement profiles across the tunnel $\mathrm{c} / \mathrm{s}$ are almost similar for all chainages. At $167 \mathrm{~m}$ Chainage due to excavation of the tunnel in predominantly soil mass the displacement profile almost follows a Gaussian distribution curve. Out of all three chainages chainage $167 \mathrm{~m}$ shows maximum vertical displacement of $0.59 \mathrm{~mm}$ followed by chainage $117 \mathrm{~m}$ of magnitude $0.27 \mathrm{~mm}$. Presence of the building loads did not alter the settlements since the soil was highly consolidated. However at Ch. $167 \mathrm{~m}$ since buildings were present on either side of the centre line of the tunnel the settlements reduced by about $0.15 \mathrm{~mm}$ at the crown. In all cases the displacements would have been considerable if the soil was normally consolidated soil (Figure 13). 


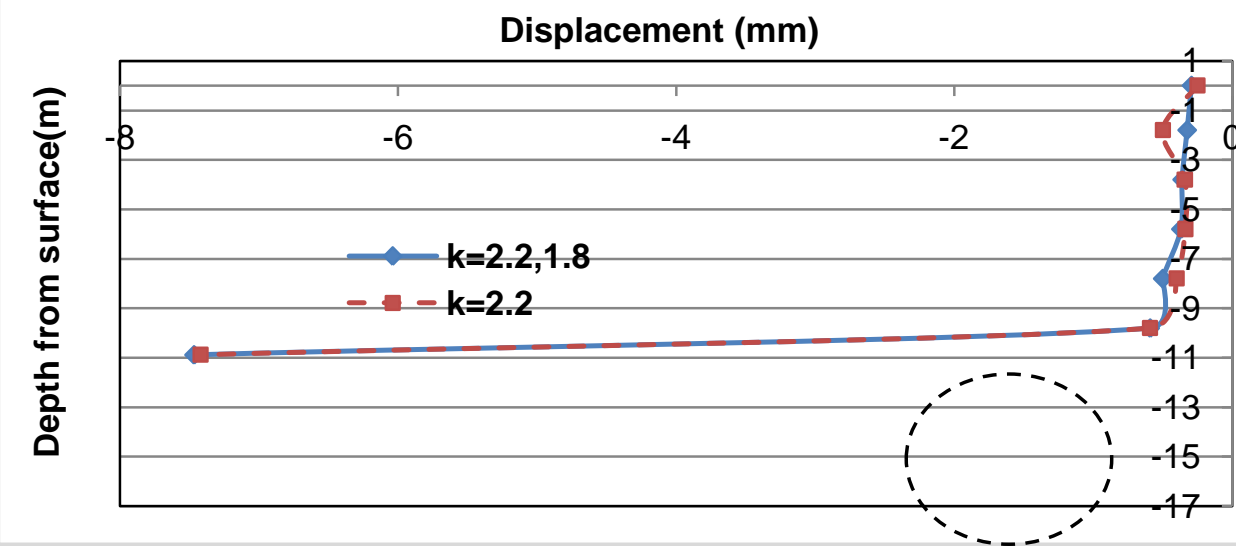

Figure 9: Vertical displacement along the depth of the tunnel at Ch. $217 \mathrm{~m}$

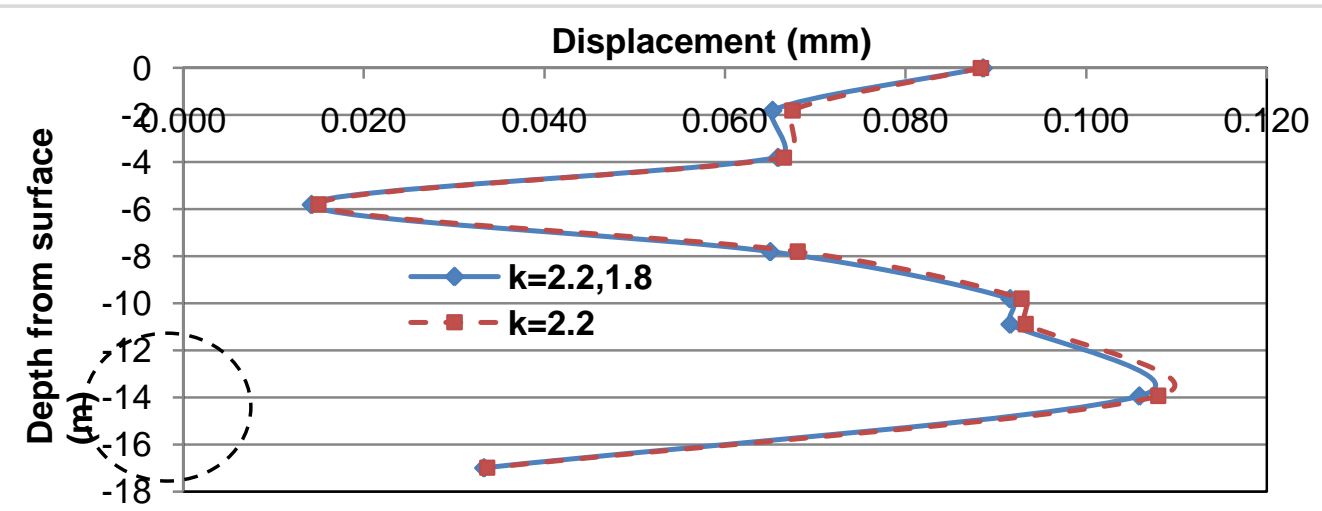

Figure 10: Horizontal displacement along the depth of the tunnel at Ch. $217 \mathrm{~m}$

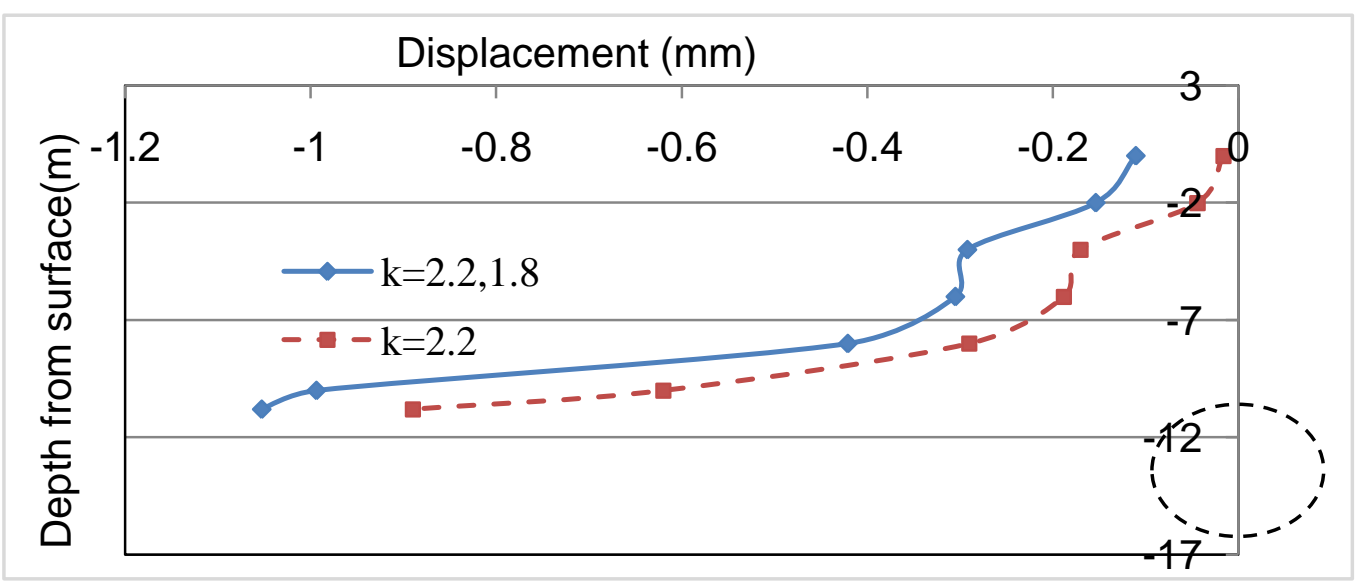

Figure 11: Vertical displacement along the depth of the tunnel at Ch. $267 \mathrm{~m}$

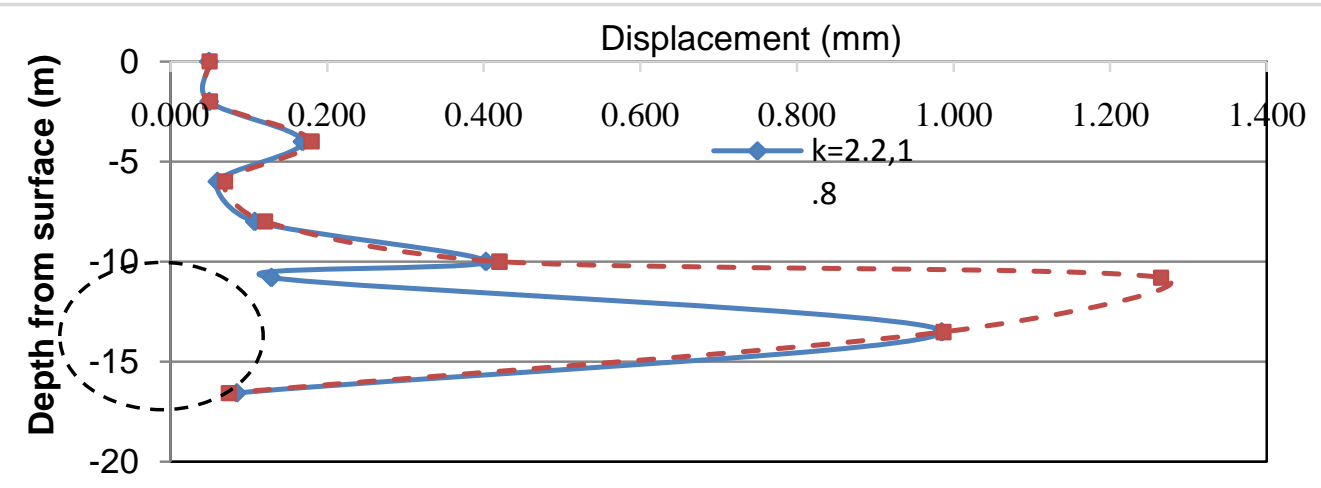

Figure. 12: Horizontal displacement along the depth of the tunnel at Ch. $267 \mathrm{~m}$ 


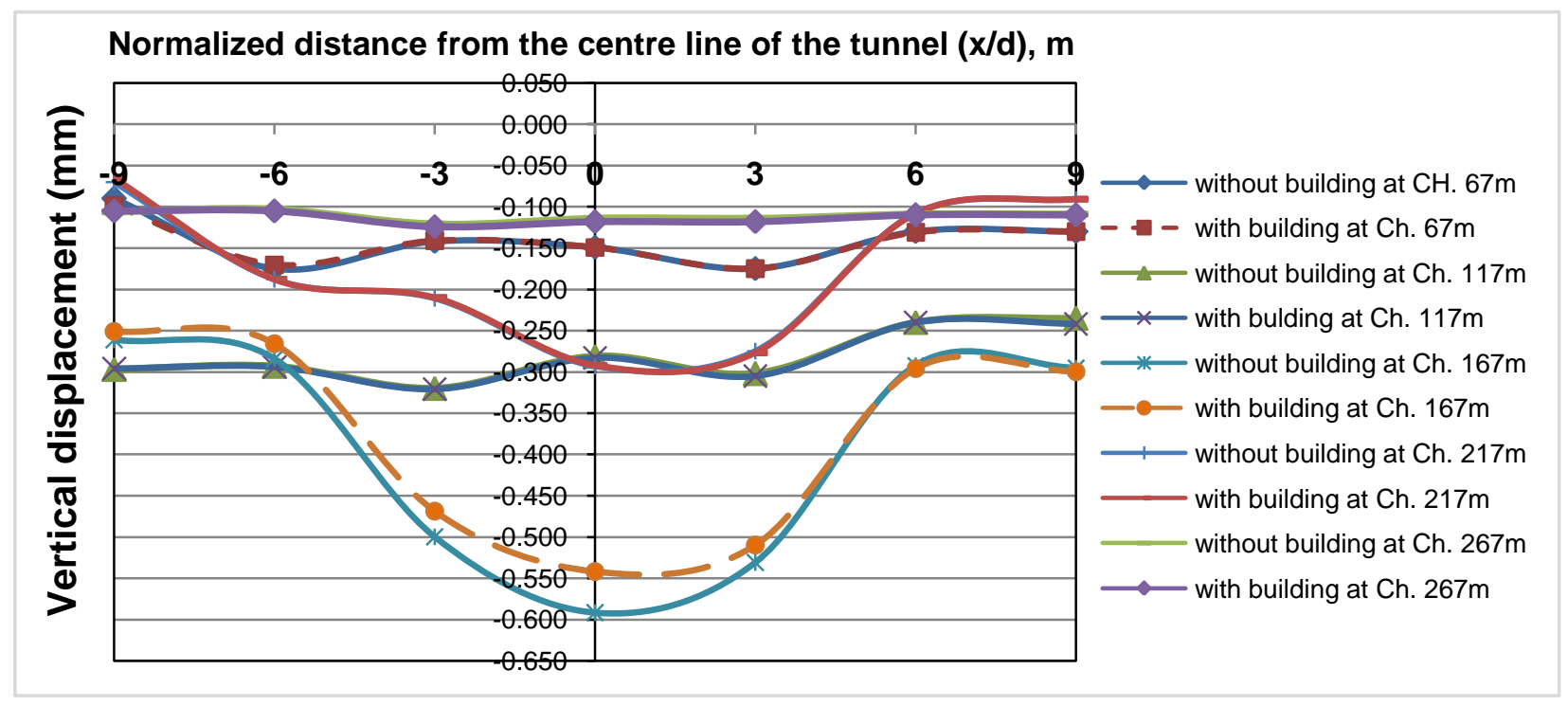

Figure 13: Vertical displacement at the surface in the transverse direction

\section{DISCUSSION}

Varying the earth pressure coefficient did not have any significant change in displacement. However, had the earth presuure coefficient been of small magnitude and a large magnitude of say 2 and above, there would have been a significant difference in the vertical displacement.

Presence of building reduced the displacement. Tunnelling in the absence of building have indicated a displacement profile which is of larger magnitude than that induced on consideration of building loads.

This study provides valuable insight in predicting changes that happen in strata surrounding tunnel, which can be correlated to displacement from field observations. All variations in strata along the length and depth of the model can be effectively incorporated with displacement predictions effectively matching the settement details obtained from site. As the 3DEC software is highly capable of modelling denser/stiffer stata, as in the current case, it will be highly beneficial for modelling similar such strata under consolidated soil conditions and in the presence of buildings.

\section{CONCLUSION}

Tunneling in soil and rock along the length led to draw the following conclusions, for tunneling in predominantly soil masses and centre line depths greater than $2 \mathrm{D}$ the displacements are not reflected to the surface. Thus at chainage $167 \mathrm{~m}$ a downward displacement of magnitude $13.9 \mathrm{~mm}$ is noted at the crown and a displacement of $1 \mathrm{~mm}$ is noted at the surface. This is because at depths greater than 2D from the surface, the upward movement of soil due to high horizontal pressures is resisted by the self weight of the soil mass/arching above the tunnel crown and thus the displacements at the surface are less.

For tunnels in predominantly rock masses the displacement at the crown is of insignificant magnitude. The tunnel crown has a downward displacement of $1.48 \mathrm{~mm}$ at Ch. $117 \mathrm{~m}, 7.5 \mathrm{~mm}$ at Ch. $217 \mathrm{~m}$ and $1.05 \mathrm{~mm}$ at Ch. $267 \mathrm{~m}$.

For all chainages the displacement at the tunnel crown is hardly reflected to the surface. At Ch. $67 \mathrm{~m}$ only $1.4 \%$ of crown displacement is reflected to the surface. Similarly at Ch. 167, 217, 267 and $317 \mathrm{~m}$ the displacement at the surface is $18.9 \%, 4.37 \%, 3.86 \%$ and $11.3 \%$ of the displacement at the crown. This is because the soil mass /rock mass is highly consolidated and no significant changes are taking place upon excavation.

Once again upon plotting the displacement along the transverse direction, the tunnel showed insignificant change in displacement due to building loads. A slight reduction in displacements was noted at points were the buildings were located. If the soil was not completely consolidated then the reduction in displacement due to building loads would have been of significant magnitude.

\section{REFERENCES}

3 DEC Manual (2004). User's guide for 3DEC, Version 3.0.

Attewell, P.B. (1978). Ground movements caused by tunnelling in soil. Proceedings of Large Ground Movements and Structures Conference. Cardiff. Pentish Press, London, Pp.812-948.

Dursun, Y., Gonhan A., Cetiner, E., and Donmez, S. (2008). Numerical Analysis of a Tunnel Support Design in Conjunction with Empirical methods. International Journal of Geomechanics 8(1): 74-81.

Kasper, T. and Meschke, G. (2006). A Numerical Study of the Effect of Soil and Grout Material Properties and Cover Depth in Shield tunnelling, Computers and Geotechnics 33(4-5): 234-246.

Lee, K.M. and Rowe, R.K. (1990). Finite element modeling of the three-dimensional ground movements due to tunneling in soft cohesive soils: part 2-results. Computers and Geotechnics 10: 111-138.

Liu, G., Houlsby, G.T., Augrade, C.E. (2000). 2-D analysis of settlement damage to Masonry Buildings caused by Tunneling. The Structural Engineer 70(1):19-25.

Peck, R.B. (1969). Deep excavations and Tunnelling in soft ground. Proc. $7^{\text {th }}$ Int. Conf. on Soil Mech. and Foundation Eng, Pp. 225-290.

Peck R.B. (1969). Deep excavations and Tunnelling in soft ground. Proceedings of the $7^{\text {th }}$ International Conference on Soil Mechanics and Foundation Engineering, Pp 225290. 